\title{
Laser Capture Microdissection As A Novel Tool For Biochemical Studies Complementing Structural Analyses
}

\author{
W.J. Landis
}

Department of Biochemistry and Molecular Pathology, Northeastern Ohio Universities College of Medicine, Rootstown, $\mathrm{OH} 44272$

The investigation of any biological tissue should ideally examine and determine its correlative structural and functional relationships. To this end, the contributions of both microscopic and biochemical parameters are critical to understanding structure-function, but analyses of these sources may be mutually exclusive and obtaining the respective data may not be straightforward. In part, some of the difficulty lies in the fact that tissue preparation for structural work may be incompatible with biochemical study of the same specimen or that biochemical methodology may preclude further microscopic consideration. Recently, a novel analytical technique, laser capture microdissection (LCM), has been developed that circumvents problems in characterizing a tissue sample by both structural and biochemical procedures. LCM provides the capability of microscopically identifying individual or clusters of cells within a tissue section and uniquely isolating ("capturing") them for a variety of subsequent molecular analyses, including those for DNA, RNA, and protein. Combined with reverse transcriptase-polymerase chain reaction (RT-PCR) analysis, for example, LCM permits a measure of gene expression of the cells of interest obtained at specific locations in a section, and therefore at known developmental times or stages of maturation. For a calcified vertebrate tissue such as bone, calcifying cartilage or tendon, dentin, cementum, or enamel, expression of genes can be correlated with degree of mineralization. By related approaches, DNA and protein may be measured biochemically and also studied in direct conjunction with tissue microstructure.

This laboratory has utilized LCM to determine gene expression correlates with microscopy as a means of gaining insight into structure-function relations in mineralizing tissues. The use of LCM in this context has necessitated a number of distinct features that incorporate application of RNAlater ${ }^{\mathrm{TM}}$ (Ambion, Austin, TX) to preserve message, frozen sectioning $\left(-20^{\circ} \mathrm{C}\right)$ of tissue mounted on aluminum stubs and embedded in OCT, cross-linking sections to slides in a CryoJane device (Instrumedics, Hackensack, NJ), fixation $(60 \mathrm{sec})$ in 70\% ethanol at room temperature, and staining $(30 \mathrm{sec})$ in eosin. LCM is performed on a Pixcell system (Arcturus Engineering, Mountain View, $\mathrm{CA})$ (Figures 1,2) whereby cells are microdissected (Figures 3,4) with a laser of $70 \mathrm{mw}$ power and $2.5 \mathrm{msec}$ duration and annealed to a thin transfer film. Cells attached to films are inserted into small tubes containing lysis buffer and $\beta$-mercaptoethanol and RNA is extracted using a protocol outlined by the NIH (http://dir.nichd.nih.gov/lcm/Protocol.htm). RNA is next DNase-treated, reversetranscribed to cDNA and amplified by PCR (40 cycles) using AmpliTaq ${ }^{\circledR}$ DNA polymerase (Applied Biosystems, Foster City, CA). Specific PCR primer pairs are designed in the laboratory. All reactions are run with appropriate positive and negative controls, and $18 \mathrm{~S}$ rRNA is used to standardize expressed message from captured cells. Typically, relative ratios of the gene of interest compared to $18 \mathrm{~S}$ are calculated from the net intensity of respective PCR products on scanned agarose gels. The relative ratio method obviates any corrections for variations in the number of cells captured in a given experiment. In this manner, expression of genes can be measured and correlated with tissue structure, leading to structure-function data in which the biochemical studies complement structural analyses $[1,2]$. 
References

[1] W.J. Landis et al., Connect. Tissue Res. 44 (Suppl. 1) (2003) 1.

[2] This research was supported by grant AR41452 from the National Institutes of Health.

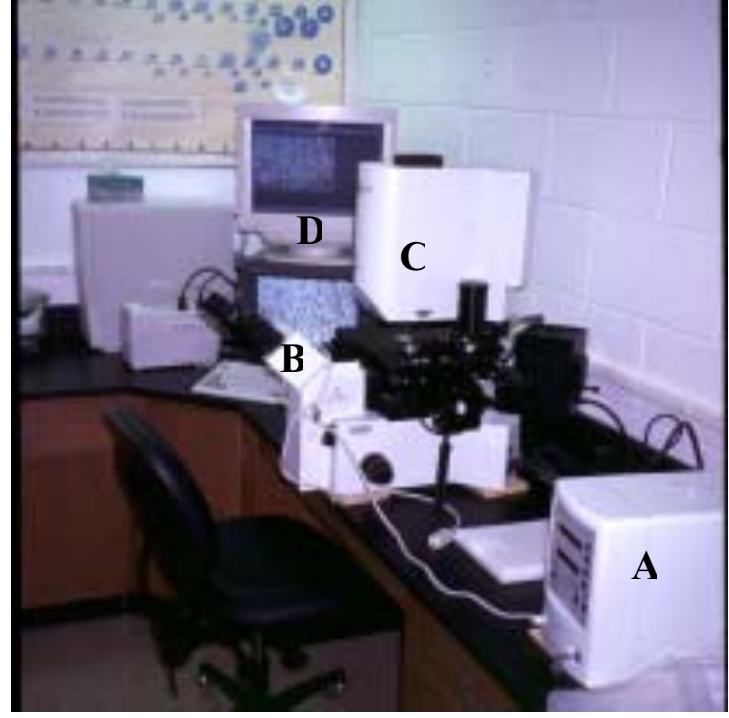

FIG. 1. Laboratory arrangement of the Pixcell LCM system, including laser power supply (A), inverted light microscope (B) interfaced with a laser (C), and computer monitor and image archival unit (D).

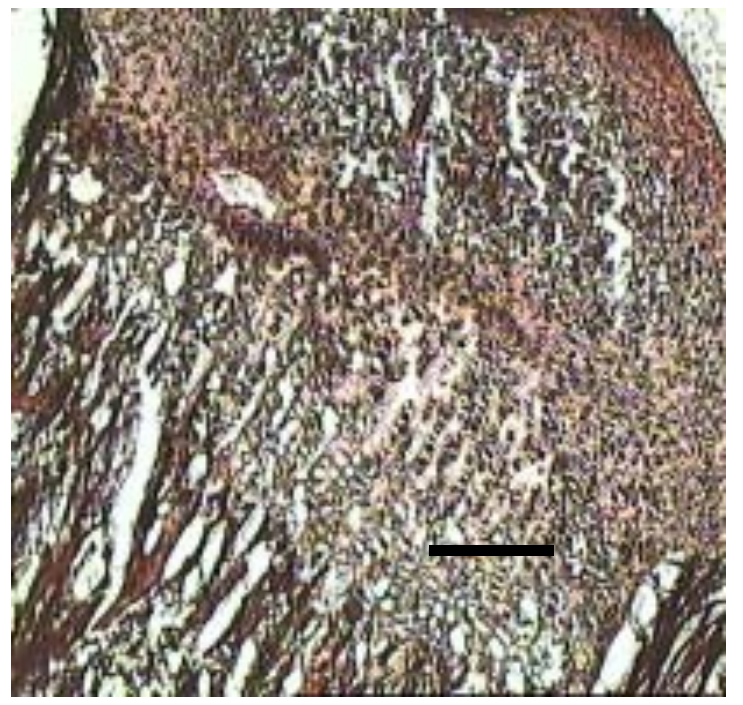

FIG. 3. Eosin-stained, $5 \mu \mathrm{m}$ thick section of the cartilaginous epiphyseal growth plate from an 8-day-old mouse tibia. Bar $=0.5 \mathrm{~mm}$

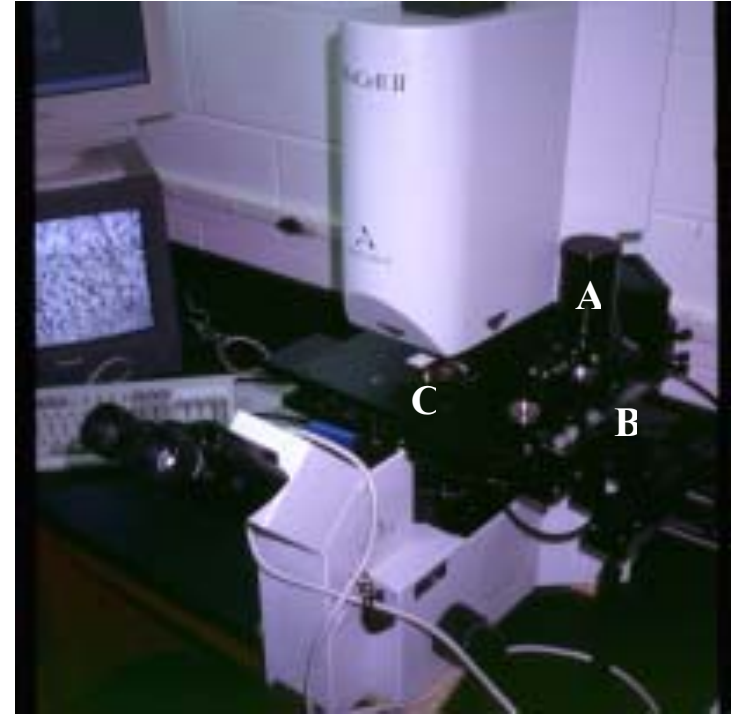

FIG. 2. View of LCM laser and microscope stage with mechanical arm (A) used to move small caps with transfer film (B) over an uncoverslipped tissue section on a glass slide (C).

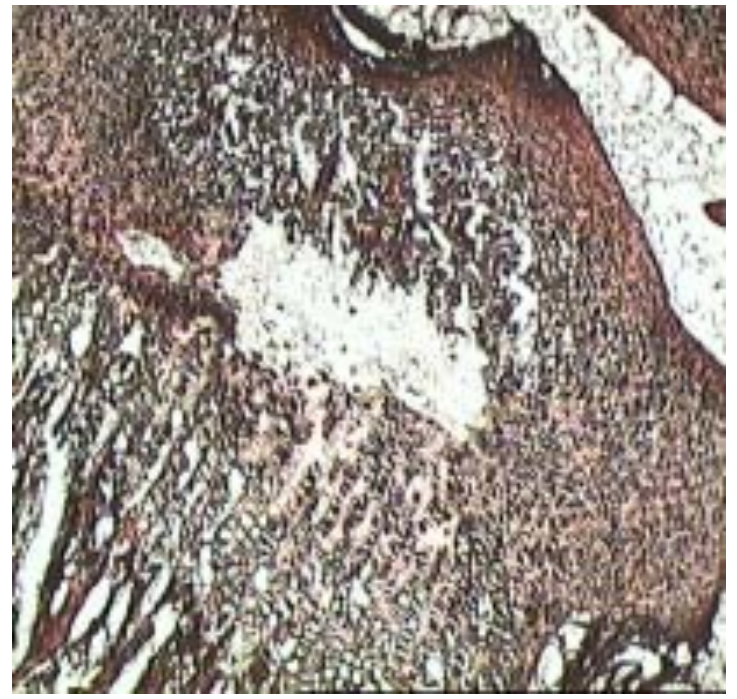

FIG. 4. The section shown in Fig. 3 after laser capture of a selected number of chondrocytes from only the proliferative zone of the growth plate. 